\title{
ERK1/2/MAPK pathway-dependent regulation of the telomeric factor TRF2
}

\author{
Vincent Picco ${ }^{1}$, Isabelle Coste ${ }^{2}$, Marie-Josèphe Giraud-Panis ${ }^{3}$, Toufic Renno ${ }^{2}$, \\ Eric Gilson $^{3,4}$, Gilles Pagès ${ }^{3}$ \\ ${ }^{1}$ Centre Scientifique de Monaco, Biomedical Department, MC-98000 Monaco, Principality of Monaco \\ ${ }^{2}$ Centre de Recherche en Cancérologie de Lyon (CRCL), INSERM U1052-CNRS UMR5286, Université de Lyon, Centre Léon \\ Bérard, 69008 Lyon, France \\ ${ }^{3}$ University of Nice, Sophia Antipolis, Institute for Research on Cancer and Aging, Nice (IRCAN), CNRS UMR7284/INSERM \\ U1081, Medical School, 06107 Nice, France \\ ${ }^{4}$ Department of Medical Genetics, Archet 2 Hospital, CHU of Nice, 06200 Nice, France \\ Correspondence to: Gilles Pagès, email: gpages@unice.fr \\ Keywords: cancer, telomere, MAP kinases, phosphorylation, DNA damage
}

Received: March 01, 2016

Accepted: May 23, 2016

Published: June 29, 2016

\section{ABSTRACT}

Telomere stability is a hallmark of immortalized cells, including cancer cells. While the telomere length is maintained in most cases by the telomerase, the activity of a protein complex called Shelterin is required to protect telomeres against unsuitable activation of the DNA damage response pathway. Within this complex, telomeric repeat binding factor 2 (TRF2) plays an essential role by blocking the ataxia telangiectasia-mutated protein (ATM) signaling pathway at telomeres and preventing chromosome end fusion. We showed that TRF2 was phosphorylated in vitro and in vivo on serine 323 by extracellular signal-regulated kinase (ERK1/2) in both normal and cancer cells. Moreover, TRF2 and activated ERK1/ 2 unexpectedly interacted in the cytoplasm of tumor cells and human tumor tissues. The expression of non-phosphorylatable forms of TRF 2 in melanoma cells induced the DNA damage response, leading to growth arrest and tumor reversion. These findings revealed that the telomere stability is under direct control of one of the major pro-oncogenic signaling pathways (RAS/RAF/MEK/ERK) via TRF2 phosphorylation.

\section{INTRODUCTION}

Telomeres are key features of linear chromosomes that preserve genome stability and function. Functional telomeres are required for stem cell biology and various types of telomere changes are involved in aging and cancer [1]. In addition to telomerase, telomere integrity relies on Shelterin, a DNA-bound protein complex composed of six polypeptides (TRF1, TRF2, RAP1, TIN2, TPP1, and POT1) [2-3]. The capping roles of this complex are to inhibit unwanted DNA damage response (DDR) activation and repair at chromosome ends, prevent telomeric DNA degradation, and regulate telomerase access and activity.

Among the Shelterin components, TRF2 is a key factor for telomere protection. TRF2 is a dimeric protein organized in four domains. At the N-terminus, a basic 45 residues domain (B domain) can interact with branched DNA structures in a manner independent of DNA sequence and protect these structures against resolution [4-5]. Following the B domain, the TRF Homology domain (TRFH) is required for homodimerization of the protein and has been recently shown to suppress ATM activation. Binding site of a number of proteins, this domain is also considered as a hub for different telomeric effectors such as Apollo or SLX4 amongst others [6-7]. The hinge domain that follows harbors sites for protein interactions such as TIN2 and RAP1 of the Shelterin complex. Finally, at the C-terminus a MYB/SANT telobox domain is responsible for telomeric sequence specific DNA binding [8-12]. TRF2 is essential for the inhibition of illicit repair of telomeres through suppression of the ATM-dependent DNA damage response and nonhomologous end joining pathways [13]. Hence, telomeres from TRF2 deficient cells become unprotected and recruit DNA damage response and repair factors often leading to chromosomes end-to-end fusions. TRF2 also protects 
telomeric sequences against replicative DNA damages, particularly those due to topological stress [14].

TRF2 protein level was shown to be increased in immortalized cells as compared to their precursor strains [15]. Moreover, TRF2 expression is increased at the RNA and protein levels in a variety of human cancers [16-20]. Notably, TRF2 protein expression level was shown to increase with the progression from normal gastric tissue to precancerous and cancerous lesions [21]. Recently, we showed that a high level of TRF2 in cancer cells represses a non-autonomous cell pathway in which cancer cells are eliminated by natural killer (NK) cells [17]. Strikingly, this function of TRF2 is not linked to its role in telomere protection, but to its ability to bind at extra-telomeric sites and to modulate gene expression [17, 22-23]. Consistent with a potent oncogenic role of a high level of TRF2, its down-regulation in a variety of cancer cells reduces tumorigenicity [17-18, 24-26].

One of the major mitogenic signaling pathways activated downstream of cell stimulation by growth factors and constitutively activated in cancer cells is the RAS/ ERK (extracellular signal-regulated kinase) pathway. Large-scale screenings using tandem mass spectrometry for phosphoproteins identified the TRF2 S323 residue of the hinge domain as being putatively phosphorylated by proline-directed kinases. TRF2 S323 residue was suggested to be a substrate for cyclin-dependent kinase 2 (CDK2) in an in vitro study where purified cyclin A-CDK2 complexes were used to treat cell lysates before recovery and sequencing of the phosphorylated peptides [27]. However, this serine residue is embedded in a suboptimal sequence for phosphorylation by CDKs [28] and no in vivo data was obtained concerning TRF2 phosphorylation by CDKs. As TRF2 S323 residue is embedded in the MAPKs consensus PXSP phosphorylation motif [29-30], we hypothesized that the well-described oncogenic alterations of the MAPK pathway and telomere maintenance could be connected via a direct phosphorylation of TRF2 by ERK1/2.

We show here that TRF2 is phosphorylated on serine 323 by ERK $1 / 2$ in both normal and cancer cells. Using in situ proximity ligation assay (PLA) [31], we demonstrate that TRF 2 and ERK $1 / 2$ physically interact in the cytoplasm of cultured cells as well as in cancer tissue samples. The expression of point-mutated non-phosphorylatable forms of TRF2 triggers telomere uncapping, growth arrest and tumor reversion. These findings reveal that telomere stability is regulated by one of the major pro-oncogenic signaling pathways (RAS/RAF/MEK/ERK) via TRF2 phosphorylation.

\section{RESULTS}

\section{TRF2 is phosphorylated by ERK1/2 on serine 323}

The role of TRF2 as a new ERK1/2 target was first investigated using an in vitro assay with recombinant active ERK2. Conditions without ERK2 or without ATP were used as negative controls. A well-known ERK1/2 substrate, GST-ELK, was used as a positive control and detected with an anti-PX[phospho]SP-specific antibody only when both recombinant active ERK2 and ATP were present (Figure 1A). GST, which was used as a negative control, was not detected by the antibody under any conditions. Phosphorylated TRF2 was detected when recombinant active ERK2 and ATP were present, suggesting that TRF2 recombinant protein could be a substrate for ERK1/2 in vitro on a serine residue contained within a PXSP motif. Only one serine residue (position 323 on the human sequence) met this criterion and was conserved among mammalian TRF2 sequences (human, monkey, mouse, rat, pig, rabbit, cow and horse) (Figure 1B). A specific antibody against the form of TRF2 phosphorylated on S323 (pTRF2) was then generated. In in vitro kinase assays, the anti-pTRF2 antibodies recognized TRF2 only when it was incubated with ATP and recombinant active ERK2 (Figure 1C). This indicates that the TRF2 phosphorylation induced by ERK2 in vitro occurs on S323.

To test whether TRF2 phosphorylation on S323 occurred in vivo, a tetracycline-inducible system was used to overexpress a wild-type form of TRF2 (WTTRF2) in the human melanoma cell line A375 which carries a BRAF ${ }^{\mathrm{V} 600 \mathrm{E}}$ activating mutation and displays strong ERK1/2 activity. When immunoprecipitation was performed with anti-pTRF2 on cells overexpressing WT-TRF2, immunoblot with TRF2 antibody revealed a band whose size corresponded to that of TRF2 (Figure 1D; direct immunoblot with anti pTRF2 failed probably because the phosphorylation site is accessible only on the native protein). Importantly, this band was not detected when the ERK1/2 activity was suppressed using PD184352, a MEK inhibitor (Figure 1D). When a mutated form of TRF2 in which S323 was replaced by an alanine $\left(\mathrm{TRF}^{\mathrm{S} 323 \mathrm{~A}}\right.$ ) was expressed, no TRF2 signal was detected in immunoprecipitation experiments using the anti-pTRF2 antibody (Figure 1D). Overall, these findings showed that ERK1/2 phosphorylates TRF2 in a S323-dependent manner both in vitro and in vivo.

\section{ERK1/2 dependent phosphorylation of endogenous TRF2 occurs in diverse cell types}

The above results were based on the detection of an over-expressed form of TRF2. To determine whether endogenous TRF2 could be phosphorylated in response to the physiological stimulation of the ERK pathway, the ERK1/2 activity was reduced by serum starvation in immortalized human fibroblasts (BJ-HELT cells) then stimulated with fetal calf serum. One hour after stimulation, ERK1/2 activity and pTRF2 peaked simultaneously (Figure 2A). Thus, the TRF2 protein was phosphorylated on S323 in response to the physiological 


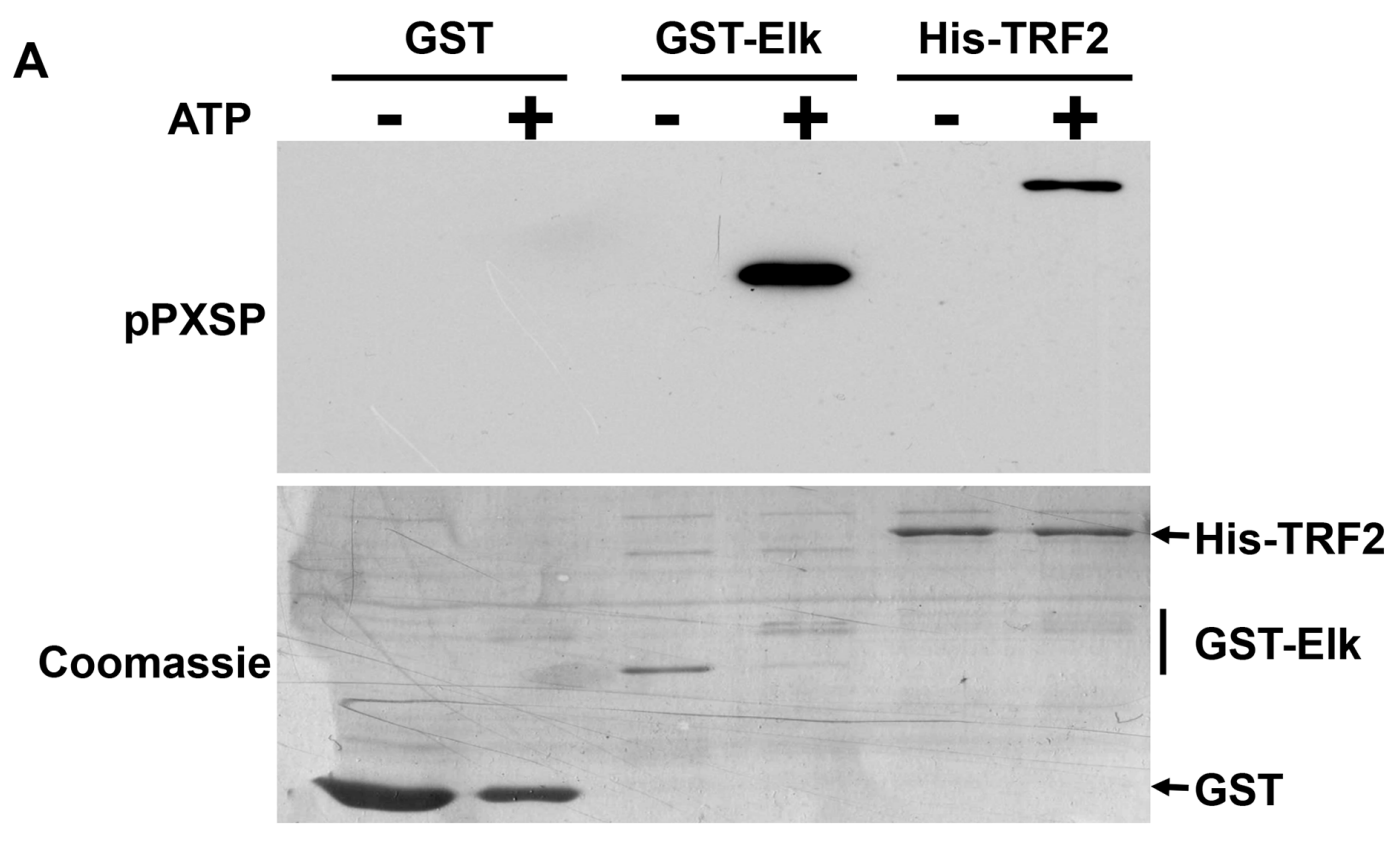

B
Homo sapiens NP_005643
Macaca mulatta $\bar{X} \mathrm{P} 001100768$
LPASPPALKNKR
Pan troglodytes X $\overline{\mathrm{P}} 001168695$
SPASPPALKNKR
Mus musculus NP_00̄̄076587.1
LPASPPALKNKR
Rattus norvegicus NP 001101918.1
SPSISPAHKHKR
Sus crofa XP_00312695 6
Oryctolagus cuniculus XP_002711707
SPSSPTHKNKR
CPP $\underline{S} P A L K N K R$
Bos taurus XP_002694884
Equus caballus XP 001916010.1
TPPISPALKNKR
CPPS्SPALKNKR
Canis familiaris $\overline{\mathrm{X}} \mathrm{P} \_546856$
SPPS्SPALKNKR

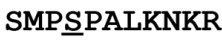

C

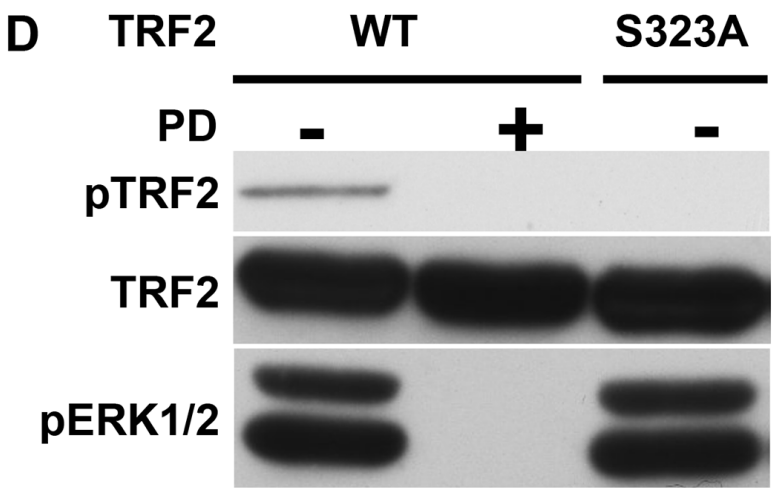

Figure 1: Identification of an ERK1/2 phosphorylation site on TRF2. A. Equimolar amounts of GST, GST-ELK and HisTRF2 were incubated in the absence (-) or presence $(+)$ of recombinant active ERK2. The phosphorylated proteins were detected after SDS PAGE using a specific anti-PX[phospho]SP antibody (pPXSP). Coomassie blue staining of the membrane is shown as a loading control. B. Alignment of TRF2 sequences from different mammalian species show the conservation of a MAPK phosphorylation consensus PXSP target site. The species and respective Genbank reference numbers corresponding to the sequences are reported. The conserved PXSP site is shown in bold and the conserved S residue underlined. C. Specificity of the immune serum using peptides containing phospho-S323. His-TRF2 was phosphorylated or not by recombinant active ERK2. The same amounts of proteins were submitted to immunoblotting analysis with the anti-pS323 antibody (pTRF2). Coomassie blue staining is shown as a loading control. D. A375 cells were stably transfected with WT-TRF2 or TRF2 ${ }^{\mathrm{S} 323 \mathrm{~A}}$. Cells were treated (+) or not (-) with PD184352 (PD). Phosphorylated TRF2 was immunoprecipitated with the specific anti-pTRF2 antibody and detected by immunoblotting with an anti-TRF2 antibody (IP). Total TRF2 is shown as a loading control (input) and pERK1/2 as a control of PD184352 activity. 
A

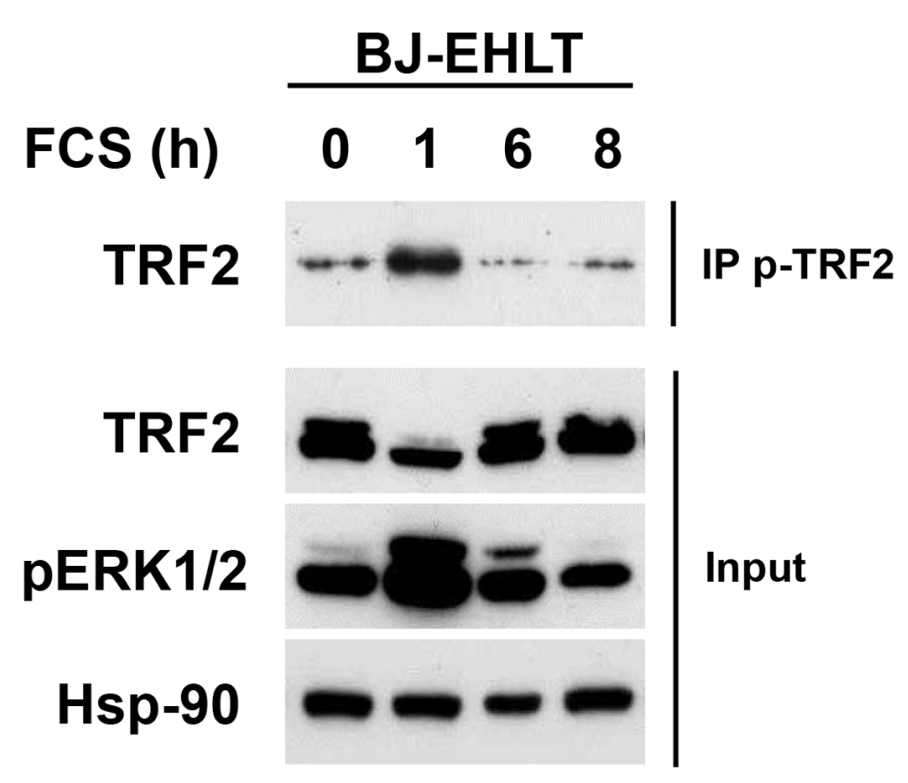

B

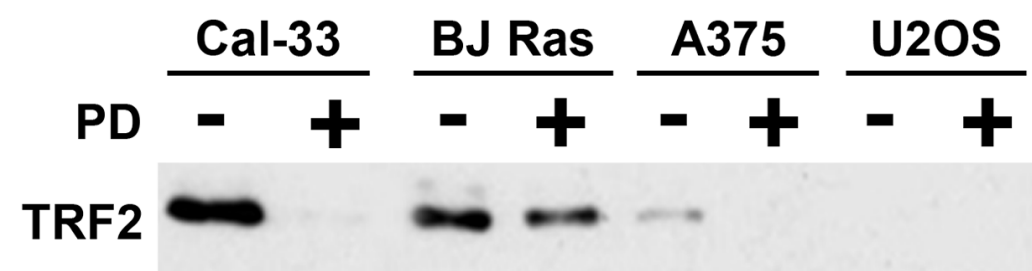

TRF2

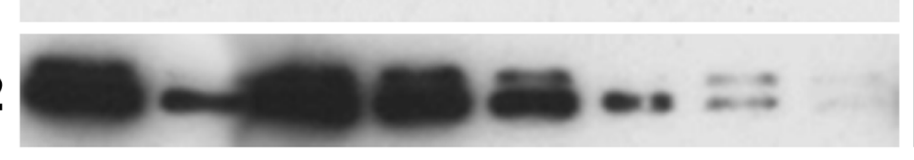

Short exp.

Long exp.

IP p-TRF2

TRF2
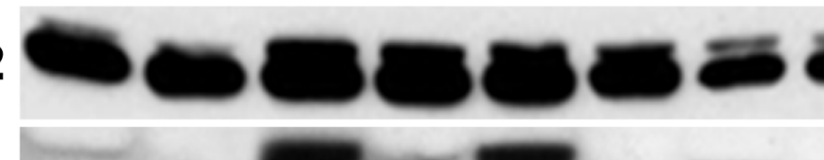

pERK1/2

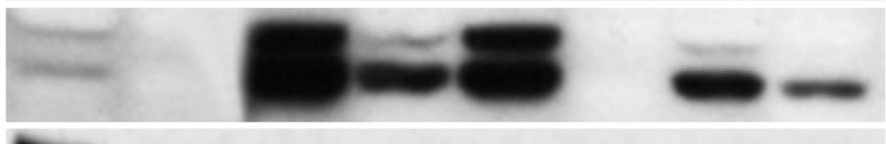

Hsp-90
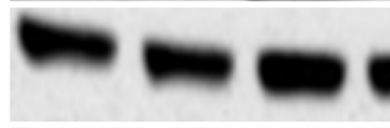

\section{Tubulin}

\section{INPUT}

Figure 2: TRF2 is phosphorylated following physiological or pathological activation of ERK1/2. A. Immortalized BJ fibroblasts were serum deprived for 24 hours. BJ cells were then stimulated with $10 \%$ FCS for the indicated times. Phosphorylated forms of TRF2 were immunoprecipitated with the specific anti-pTRF2 antibodies and detected by immunoblotting with an anti-TRF2 antibody (IP p-TRF2). Total TRF2 and Hsp-90 are shown as loading controls and the phosphorylated forms of ERK1/2 as a control of serum-dependent activation of ERK1/2 (Input). B. Different tumor cells were tested for the presence of pTRF2 by immunoprecipitation in the presence $(+)$ or absence (-) of PD184352 (PD) (Cal33, BJ-Ras (BJ-R), A375, U2OS). A short (Short exp.) and long (Long exp.) exposure of the blots are shown (IP p-TRF2). Total TRF2, Hsp90 and tubulin are shown as loading controls and the phosphorylated forms of ERK1/2 as a control of PD184352 activity (Input). 
stimulation of ERK1/2. To translate this result to a cancer context, the pTRF2 level was measured in different tumor cell lines with constitutive ERK1/2 activity (Cal33 cells overexpressing the EGF receptor, BJ-HELT RAS cells expressing H-RAS V12, A375 cells with B-RAF ${ }^{\mathrm{V} 600 \mathrm{E}}$ mutation and U2OS cells overexpressing PDGF and IGFI/II receptors). In these cells, pTRF2 was inhibited by PD184352, suggesting that pTRF2 is dependent on mutations activating the ERK pathway (Figure 2B). These results show that TRF2 phosphorylation by ERK1/2 is a common process in cancer cells of various origins.

\section{ERK1/2 and TRF2 physically interact in the cytoplasm}

Although TRF2 in vitro phosphorylation suggested that this protein could interact with phosphorylated/ activated ERK1/2 (pERK), this point needed to be further explored. An evolutionary conserved consensus sequence for ERK1/2 interaction called the D domain was present close to S323 between amino acids 353 and 364 of TRF2 (KNKRMTISRLVL) [32] (Supplementary Figure S1). As the interaction between $\mathrm{pERK} 1 / 2$ and its substrates is very labile, we used the highly sensitive in situ PLA technique [31] to detect a physical interaction between TRF2 and pERK1/2. Such an interaction was shown in A375 cells (Figure 3A) and it was strongly decreased when ERK1/2 phosphorylation was inhibited by treatment with PD184352 (Figure 3A and Supplementary Figure S2). These results demonstrate that TRF2 and pERK1/2 physically interact in cultured cells. We then attempted to confirm the interaction between TRF2 and pERK1/2 on tumor tissue samples. Using PLA, we showed that TRF2 interacts with pERK1/2 in three different cancers with constitutively active ERK1/2: cutaneous squamous cell carcinomas, lung squamous cell carcinoma and cervical squamous cell carcinoma but not in their normal tissue counterparts (Figure 3B). PLA signal on tissue microarray is faint or inexistent in normal skin while it was stronger in various skin cancer samples (Supplementary Figure S3 and Supplementary Table S1). This result suggests a slight or no interaction between TRF2 and pERK1/2 or a lack of pERK1/2 in normal skin. Unexpectedly, confocal microscopy imaging followed by $3 \mathrm{D}$ image reconstruction showed that TRF2 and pERK1/2 do not interact in the nucleus but rather in the cytoplasm of both A375 cells and squamous cell carcinoma samples (Figure 3A and 3B). As the telomeric protein TIN2, a physiological partner of TRF2, can be localized in mitochondria [33], we tested whether TRF2 and pERK1/2 interacted in these organelles. The use of a mitotracker failed to demonstrate a co-localization of TRF2 and pERK1/2 signals in mitochondria (Supplementary Figure S4). The unexpected cytoplasmic location of TRF2 suggests a new specific role of TRF2 in the cytoplasm that should be further investigated. Taken together, these results strongly suggest that TRF2/ERK1/2 physical interaction preferentially occurs in cancer cells.

\section{Increased TRF2 half-life is an ERK1/2- dependent mechanism}

The consequences of ERK1/2-dependent phosphorylation of TRF2 were then investigated. No difference in DNA binding affinity between the phosphorylated and the non-phosphorylated forms of TRF2 was detected (Supplementary Figure S5). In addition, the ability of ERK1/2 to control TRF2 half-life was assessed. TRF2 was highly stable in A375 cells with a half-life longer than eight hours (Supplementary Figure S6A). After sixteen hours of cycloheximide treatment, TRF2 expression was only slightly decreased in cell lines with constitutive ERK1/2 activity (A375 and SKMel-51 melanoma cells with $\mathrm{BRAF}^{\mathrm{V} 600 \mathrm{E}}$ mutation and BJ-HELT RAS, Figure 4A and 4B). Indeed, a marked decrease in TRF2 expression was observed after sixteen hours of cycloheximide treatment in the presence of PD184352 (Figure 4A and 4B). While cycloheximide did not significantly decrease WT-TRF2, TRF2 ${ }^{\mathrm{S} 323 \mathrm{~A}}$ expression was strongly reduced (Figure 4C). Mutation of S323 to glutamic acid resulted in a similar down-regulation of protein stability (Supplementary Figure S6B). We concluded that the phosphorylation of S323 is crucial for ERK1/2-dependent TRF2 half-life increase. These findings suggest that ERK1/2 participate in telomere protection and favor neoplastic growth by maintaining TRF2 levels.

\section{TRF2 $^{\text {S323A }}$ expression induces telomere dysfunction, apoptosis and senescence in A375 cells}

We then investigated whether the nonphosphorylatable forms of TRF2 could affect A375 melanoma cell proliferation. The dominant-negative form of TRF2, TRF2 ${ }^{\triangle \mathrm{B} \Delta \mathrm{M}}$, was used as a positive control for TRF2 dysfunction [25]. While overexpressing WTTRF2 did not affect functionality of the telomeres, $\mathrm{TRF} 2^{\mathrm{S} 323 \mathrm{~A}}$ or TRF2 ${ }^{\triangle \mathrm{B} \Delta \mathrm{M}}$ expression during four days led to accumulation of telomeric induced foci (TIFs) as assessed by co-staining of the DNA-damage response factor 53BP1 and the telomeres (Figure 5A). Overexpression of WT-TRF2 did not affect the cell cycle as compared to control cells. Instead, TRF $2^{\mathrm{S} 323 \mathrm{~A}}$ or TRF $2^{\triangle \mathrm{B} \Delta \mathrm{M}}$ expression during four days led to accumulation of cells showing fragmented DNA (sub-G1 phase) that is characteristic of apoptotic cells (Figure 5B). The same result was obtained when TRF2 ${ }^{\mathrm{S} 323 \mathrm{E}}$ mutant was expressed (Supplementary Figure S7A), suggesting that this mutant rather acts as a non-phosphorylatable form of TRF2. This phenotype was accompanied by activation of the tumor suppressor p53 (Figure 5E). We then assessed proliferation and survival of these cells in a clonogenic assay. Very few cells remained after eight days of expression of $\mathrm{TRF}^{\triangle \mathrm{B} \Delta \mathrm{M}}, \mathrm{TRF}^{2 \mathrm{~S} 323 \mathrm{~A}}$ (Figure $5 \mathrm{C}$ ) or $\mathrm{TRF}^{\mathrm{S} 323 \mathrm{E}}$ mutants (Supplementary Figure S7B). All the surviving cells 
were quiescent and expressed $\beta$-galactosidase, features of senescent cells (Figure 5D and Supplementary Figure $\mathrm{S} 7 \mathrm{C}$ ). These results indicate that the over-expression of non-phosphorylatable forms of TRF2 impairs cell proliferation and survival by triggering telomere dysfunction, apoptosis and senescence.

\section{Mutation of S323 to unphosphorylatable amino- acid prevents the pro-tumor effect of TRF2}

Finally, the impact of TRF2 $2^{\mathrm{S} 323 \mathrm{~A}}$ or TRF2 ${ }^{\mathrm{S} 323 \mathrm{E}}$ on the tumorigenic properties of A375 cells was investigated. Control A375 cells and A375 cells conditionally expressing WT or mutant TRF2 were subcutaneously injected into nude mice. The transgene expression was induced with doxycycline ten days after injection. WT-TRF2 overexpression accelerated tumor growth while the expression of the mutant forms of TRF2 had no effect (TRF2 ${ }^{\mathrm{S} 323 \mathrm{~A}}$ ) or slightly decreased (TRF2 ${ }^{\mathrm{S} 323 \mathrm{E}}$ ) tumor growth (Figure 6A and Supplementary Figure S7E). These results demonstrated that the S323 mutation to non-phosphorylatable residues inhibits the ability of TRF2 to stimulate tumor growth.

\section{DISCUSSION}

The main result of this work is the link between MAP kinase activity and telomere protection via TRF2 phosphorylation. Specifically, TRF2 is phosphorylated on serine 323 by ERK1/2 in both normal and cancer cells. Non-phosphorylatable forms of TRF2 are less stable as compared to the wild-type form and alter telomere capping in a dominant negative manner.

These findings suggest that the constitutive activation of MAP Kinase signaling in cancers leads to an increased
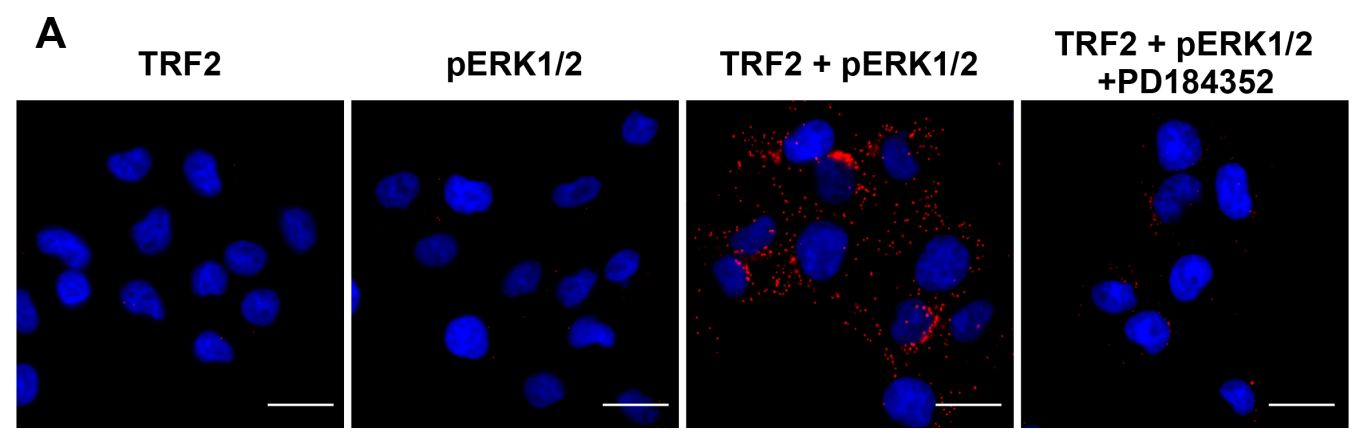

3D reconstruction

B
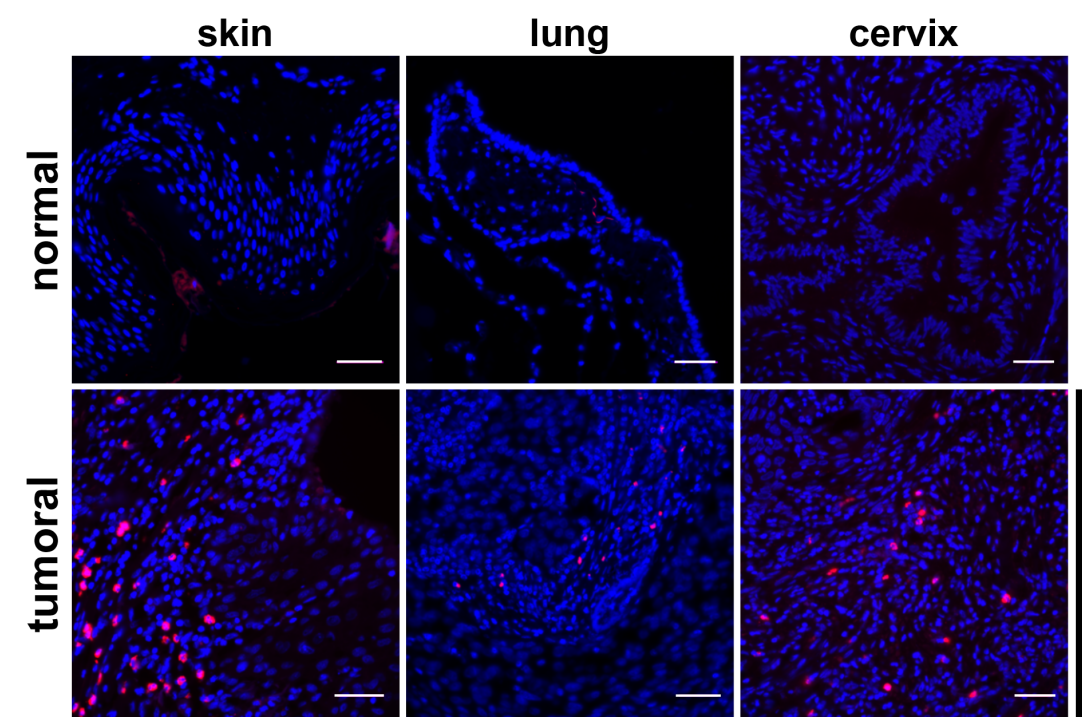

$3 \mathrm{D}$ reconstruction (skin tumor)

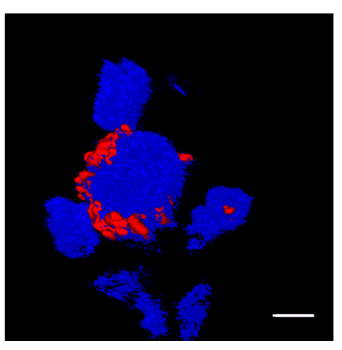

Figure 3: TRF2 and pERK1/2 interact in the cytoplasm of a melanoma cell line and human cancer samples. A. In situ proximity ligation assay (PLA) with anti-TRF2 and anti-pERK1/2 antibodies alone (negative controls, but in the presence of the two secondary antibodies) or in combination (TRF2 + pERK1/2) in A375 cells in the presence of DMSO or PD184352 (scale bars represent $10 \mu \mathrm{m})$. A 3D image reconstruction after confocal microscopy imaging of PLA with a combination of anti-TRF2 and anti-pERK1/2 antibodies is also shown (scale bar represents $1 \mu \mathrm{m}$ ). B. PLA with combined anti-TRF2 and anti-pERK antibodies in normal human skin tissue or cutaneous squamous cell carcinoma, normal lung or lung squamous cell carcinoma and normal cervix or cervical squamous cell carcinoma (scale bars represent $35 \mu \mathrm{m}$ ). A 3D image reconstruction after confocal microscopy imaging of PLA with a combination of antiTRF2 and anti-pERK1/2 antibodies in cutaneous squamous cell carcinoma is also shown (scale bar represents $1 \mu \mathrm{m}$ ). 
TRF2 level and telomere protection, which are parameters favoring neoplastic growth. Consistent with our previous results [17], we found that WT-TRF2 overexpression accelerates tumors growth in xenograft experiments. Instead, the expression of non-phosphorylatable forms of TRF2 did not increase the tumorigenic properties of the melanoma cell line. This result suggests that TRF2 phosphorylation on $\mathrm{S} 323$ is required for TRF2 prooncogenic capacities. Notably, this result seems discrepant with our in vitro data showing that expression of TRF2 non-phosphorylatable mutants induces cell death and senescence. Hence, tumors should have not developed with cells expressing these mutant forms of TRF2. We previously showed that IL6 plays a protective role towards the loss of TRF2 [17]. IL6 present in the tumor microenvironment may play a protective role for the cancer cells.
Besides, the similar half-lives and properties of $\mathrm{TRF}^{\mathrm{S} 323 \mathrm{~A}}$ and $\mathrm{TRF} 2^{\mathrm{S} 323 \mathrm{E}}$ mutants were the opposite of what was anticipated.Based on our own experiments, negatively charged amino acids like aspartic or glutamic acids do not mimic phosphorylated residues in all the cases. If not, the protein behaves as an unphosphorylatable protein. The most obvious examples are ERK1/2 for which the change in tyrosine and threonine residues of the catalytic domain to glutamic or aspartic acid has no effect on the kinase activity. Moreover, these ERK1/2 mutants behave as dominant negative forms ([34] and GP unpublished results). Hence, we assumed that TRF2 belongs to this category of proteins. Together with previous works showing that TRF2 is a direct target of the canonical Wnt signaling pathway [16] and is downregulated upon p53 activation [35], our results highlight
A

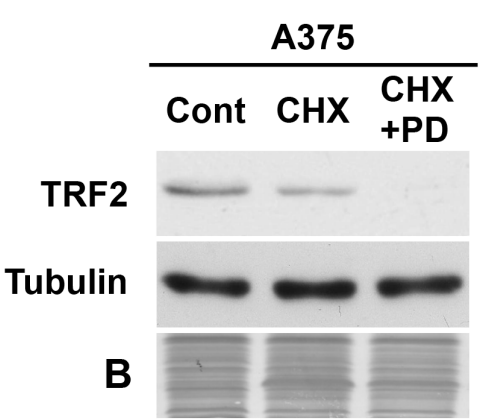

B

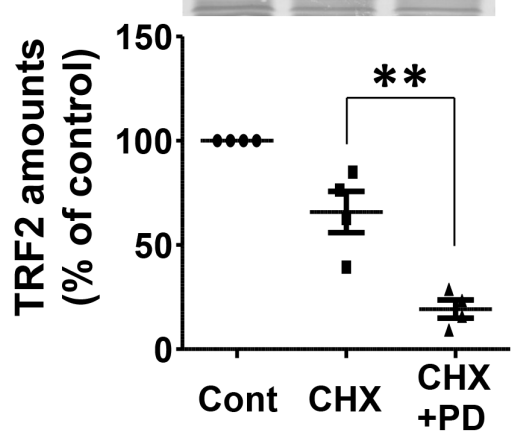

C

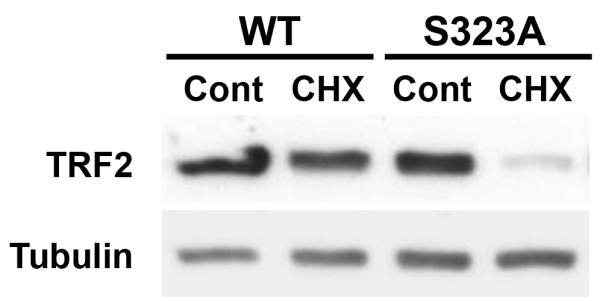

SkMel-51

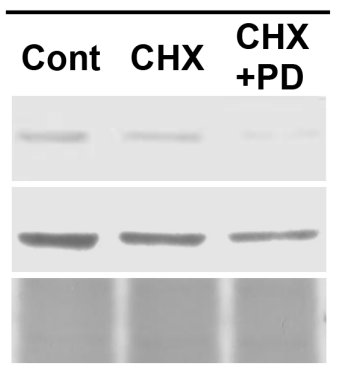

150

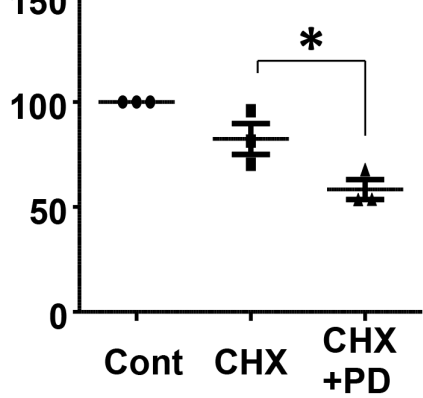

BJ-Ras

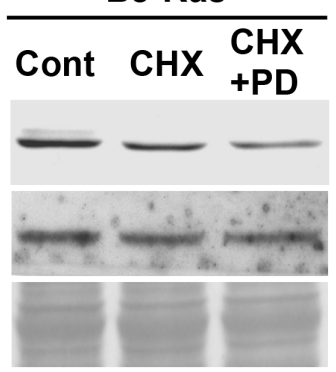

150
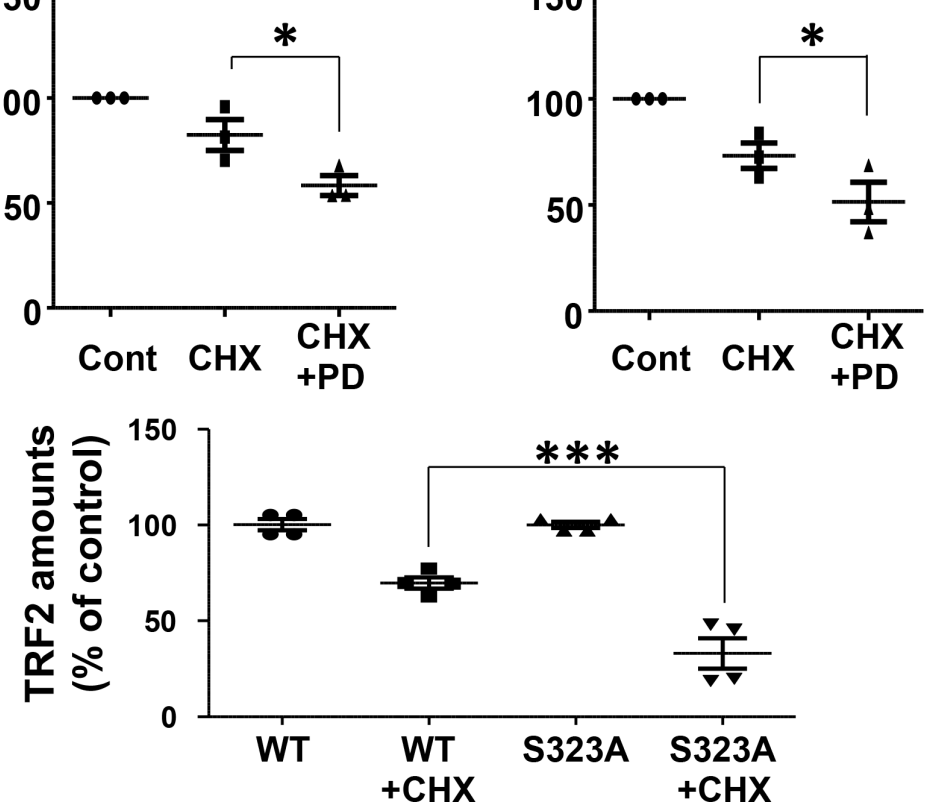

Figure 4: TRF2 half-life is dependent on TRF2 phosphorylation of S323 by ERK1/2. A. A375, SKMel-51 and BJ-RAS cells were incubated in the presence of $50 \mu \mathrm{g} / \mathrm{ml}$ cycloheximide (CHX) for 16 hours in the presence or absence of PD184352 (PD). Total TRF2 and tubulin amounts were evaluated by immune-blotting. Tubulin and coomassie blue staining of the membrane (B) are shown as loading controls. B. Densitometric quantifications of the blots shown in A. The TRF2 expression level was normalized with three to four different loading controls and expressed relative to the control conditions (results are expressed as mean $\pm \mathrm{SD}$ ). One way ANOVA statistical analysis is included: $* \mathrm{p}<0.05 ; * * \mathrm{p}<0.01 ; * * \mathrm{p}<0.001)$. C. A375 cells over-expressing either TRF2-WT or TRF2-S323A were incubated in the presence of $50 \mu \mathrm{g} / \mathrm{ml}$ cycloheximide for 16 hours. Tubulin is shown as loading control. Densitometric quantification of the blot is shown (results are expressed as mean $\pm \mathrm{SD}$. One way ANOVA statistical analysis is included: ${ }^{*} \mathrm{p}<0.05 ; * * \mathrm{p}<0.01 ; * * * \mathrm{p}<0.001$ ). 
the notion that TRF2 is the target of several key oncogenic signaling pathways. This is consistent with the tumor suppressive effects of telomere dysfunction [36] and the oncogenic activities of TRF2 [17, 24-26]. In addition to its crucial role in cancer cells, MAP Kinase signaling represents one of the most central pathways required for growth control, normal development and differentiation in most tissues as well as environmental response. Our results suggest that TRF2 levels and telomere protection are subject to modulations by MAP Kinase signaling. Indeed, cell growth might require to be coupled to TRF2dependent telomere functions in order to ensure proper cell division.

The telomere dysfunctions and growth defects triggered by $\mathrm{TRF} 2^{\mathrm{S} 323 \mathrm{~A}}$ or $\mathrm{TRF} 2^{\mathrm{S} 323 \mathrm{E}}$ might directly result from their inability to be phosphorylated by the MAP Kinase pathway. Another possibility could be that these mutants form stable complexes with the kinase. Indeed, a consensus sequence for ERK1/2 interaction is present close to Ser 323 between amino acids 352 and 365 of TRF2 (KNKRMTISRLVLE) [32]. Since this region corresponds to the docking site of TIN2 (Frescas \& de Lange, 2014), the formation of stable TRF2-kinase complex because of the presence of non-phosphorylatable forms of TRF2 may impair the interaction between TRF2 and TIN2, thereby disrupting Shelterin organization and capping function [37-38]. Inactive forms of ERK1/2 may also form stable complexes with TRF2, hence preventing interaction with TIN2 which could explain, at least in part, the anti-proliferative effect observed for mutant

A
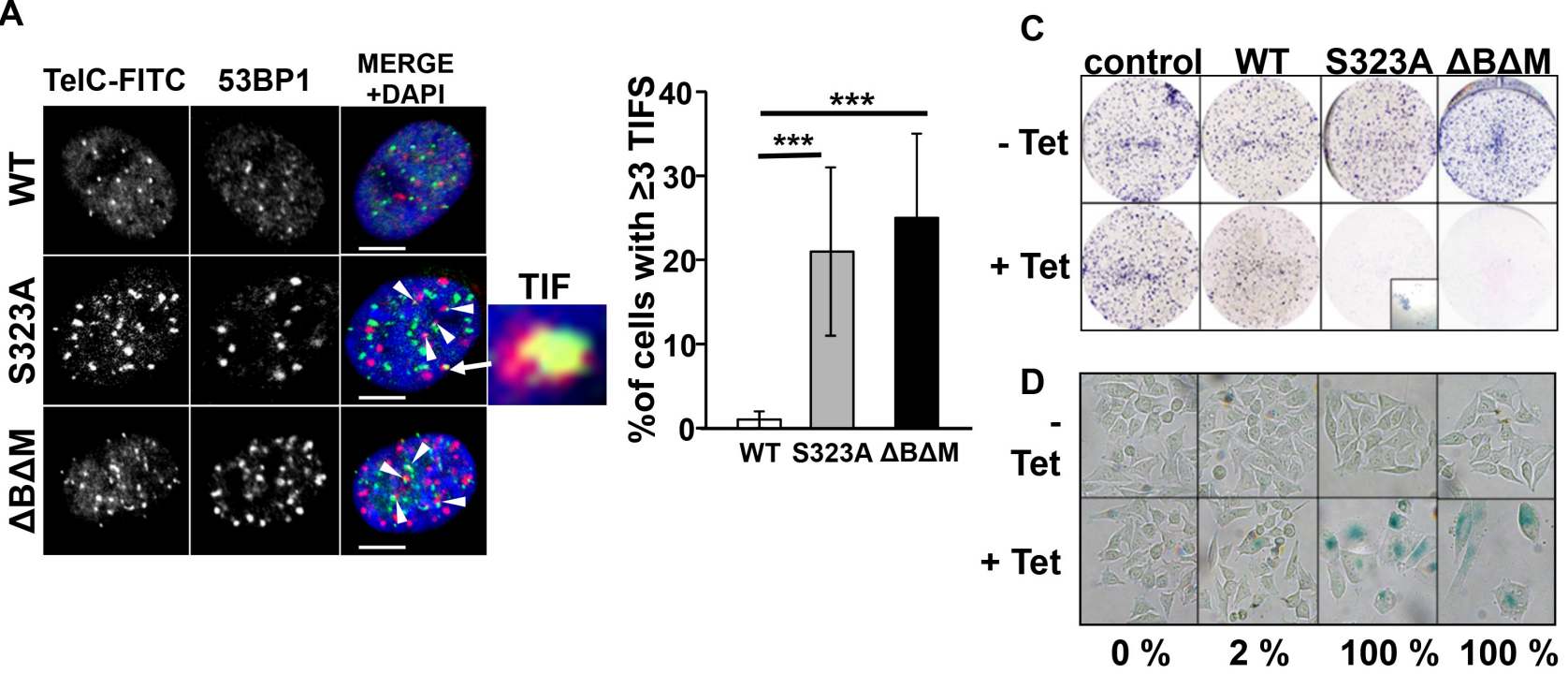

B
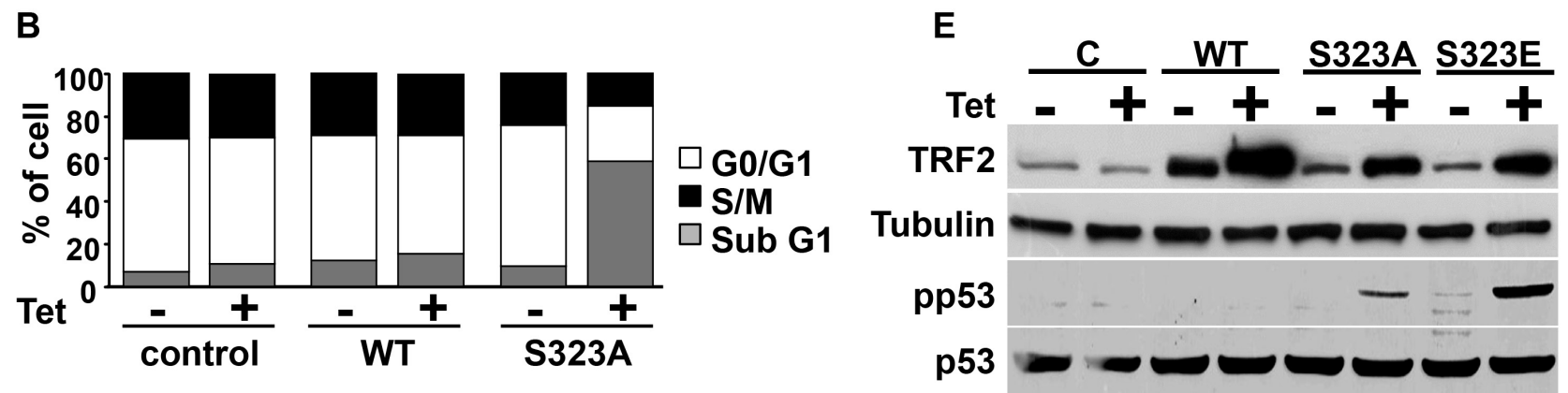

Figure 5: Expression of mutant forms of TRF2 induces telomere defects, apoptosis and senescence. A. Confocal imaging of the co-staining of 53BP1 by immunofluorescence (red) and telomeres by fluorescent in situ hybridization (TelC-FITC, green) in A375 cells were the expression of WT-TRF2, TRF2 ${ }^{\mathrm{S} 323 \mathrm{~A}}$ or TRF2- $\triangle \mathrm{B} \Delta \mathrm{M}$ was induced by tetracycline (Tet) treatment. Colocalisation events were counted as Telomere dysfunction-Induced Foci (TIF, indicated with white arrows, scale bars represent $5 \mu \mathrm{M}$ ) and the proportion of nuclei showing more than 3 TIF is indicated (right panel, results are expressed as mean $\pm \mathrm{SD}$, t-test statistical analysis is included: $* \mathrm{p}<0.05 ; * * \mathrm{p}<$ $0.01 ; * * \mathrm{p}<0.001)$. B. The proportion of cells in each phase of the cell cycle was determined by DNA labeling with propidium iodide and FACS analysis. Sub G1 stands for cells with fragmented DNA, a hallmark of apoptosis. C. Conditional overexpression of different forms of TRF2 (WT, TRF2 ${ }^{\mathrm{S} 323 \mathrm{~A}}$ and TRF2 ${ }^{\triangle \mathrm{B} \triangle \mathrm{M}}$ ) was induced by tetracycline (Tet) in A375 cells. Seven days after tetracycline stimulation, cells were colored with giemsa blue. A close-up in TRF2 ${ }^{\mathrm{S} 323 \mathrm{~A}}$ overexpression well shows the few remaining cells at the end of the experiment. D. The cells were tested for b-galactosidase activity after seven days of tetracyclin induction (lower pictures). The percentage of $\beta$-galactosidase positive cells under tetracycline-induced conditions is specified below the images. E. Seven days after induction of the different forms of TRF2 by tetracycline (+), cells were tested for the presence of phosphorylated forms of p53. Actin and p53 are shown as loading controls. 
forms of ERK1/2 [34]. Conversely, the presence of active forms of ERK1/2 may prevent stable ERK1/2/TRF2 interactions to occur and thus favors proper Shelterin assembly in normal situations. Indeed, subtle ERK1/2 activity regulation is required all along the cell cycle for a physiological G1/S and G2/M transition. Although ERK1/2 activity is decreased during the $\mathrm{S}$ phase compared to its activity during $\mathrm{G} 1$ and $\mathrm{M}$ phases, a basal ERK1/2 activity persists all along the cell cycle [39]. The increased
TRF2 half-life caused by sustained ERK1/2 activity that we observed in cancer cells might become a key factor to maintain telomere capping, cell proliferation and survival in a context of genome instability. This ERK1/2dependent TRF2 stabilization might counteract the p53dependent degradation of TRF2 [35] and control the turn-over of TRF2 binding at telomeres since different pools of telomere-bound TRF2 molecules exist in vivo [40]. In the paper of Fujita et al [35], TRF2 half-life

A

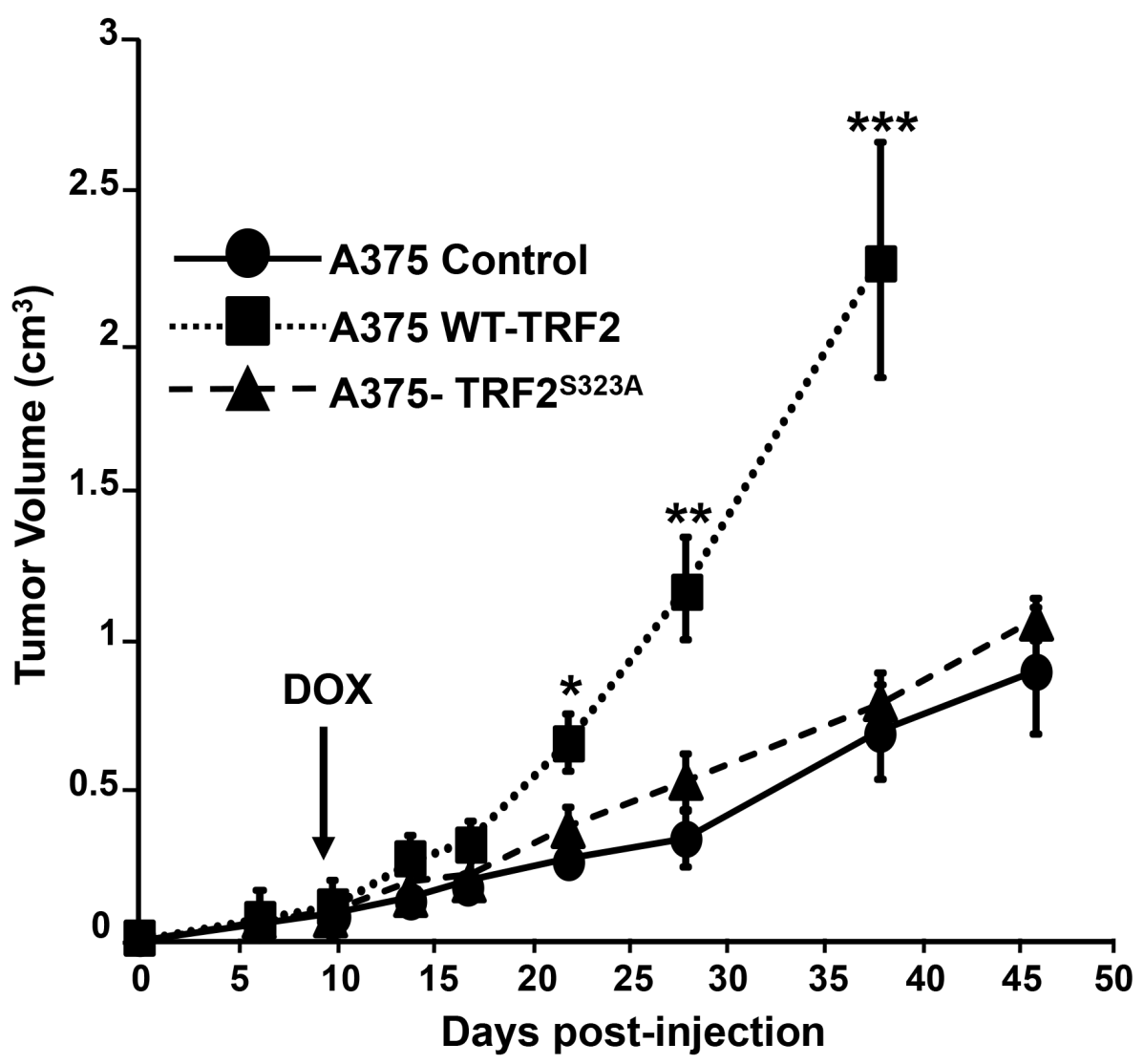

B

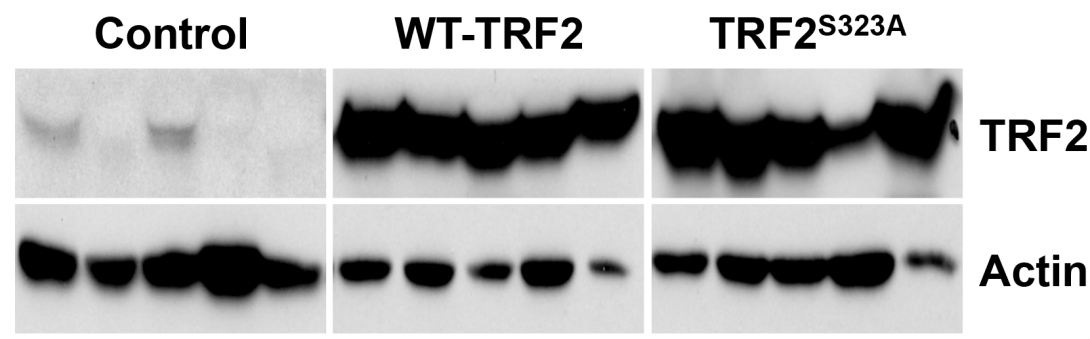

Figure 6: Effects of TRF2 mutant on tumorigenesis in nude mice. A. Control A375 cells or A375 cells conditionally expressing WT-TRF2 or TRF2 ${ }^{\mathrm{S} 323 \mathrm{~A}}$ were subcutaneously injected into nude mice. Doxycycline was added to the drinking water ten days after injection to induce the transgenes expression. The tumor volume is shown and results are expressed as mean $\pm \mathrm{SD}$ (t-test statistical analysis is included: $* \mathrm{p}<0.05 ; * * \mathrm{p}<0.01 ; * * * \mathrm{p}<0.001)$. B. Immunoblots showing the expression of TRF2 and actin (loading control) in tumor extracts prepared at the end of the tumor xenograft experiment. 
was tested on nuclear extracts of primary fibroblasts. In these cells, nuclear TRF2 has a four hours half-life. In our experiments, TRF2 has a ten hours half-life on total tumor extracts (Laemmli lysates, a mix of nuclear and cytoplasmic TRF2, Figure 4) and primary cells (keratinocytes and fibroblasts, Supplementary Figure S8). The TRF2 half-life in the two cellular compartments may be different probably because phosphorylated ERK1/2 amounts are more important in the cytoplasm and could phosphorylate and stabilize TRF2 [41].

Overall, these findings reveal a direct link between the ERK/MAP kinase pathway and telomere stability, two universal features of tumor cells. These results suggest an integrated mode of growth control, coupling telomere stability to proliferation.

\section{MATERIALS AND METHODS}

\section{In vitro phosphorylation assays}

$2 \mu \mathrm{g}$ of His-TRF2, GST-Elk or GST recombinant proteins were added to a reaction mix in the presence or absence of an active recombinant ERK2 protein (Ozyme) in the appropriate buffer. Proteins were then separated on a SDS gel, transferred onto polyvinylidene difluoride membranes that were blotted either with a phosphoMAPK/CDK substrate (Cell Signaling Technology) or a rabbit polyclonal phospho-TRF2 antibody (see below).

\section{Constructs and cell lines}

The details on the DNA constructs generated during this study will be given upon request. All cell lines used in this study were cultured in Dulbecco's Modified Eagle's Medium (DMEM, Invitrogen) supplemented with 10\% heat-inactivated fetal calf serum (PAF) at $37^{\circ} \mathrm{C}$ in an atmosphere of $5 \% \mathrm{CO}_{2}$ and supplemented with selection antibiotics as follow: $10 \mu \mathrm{g} / \mathrm{mL}$ blasticidine for A375 melanoma cells expressing the Tetracycline repressor gene; $400 \mu \mathrm{g} / \mathrm{ml} \mathrm{G} 418$ for neomycin, $100 \mu \mathrm{g} / \mathrm{ml}$ hygromycin for BJ HELT and BJ-RAS immortalized fibroblast.

A375 cells were kindly provided by Dr Robert Ballotti, specialist of the melanoma field of research and were authenticated by direct sequencing of the B-RAFV600E mutation. Immortalized BJ fibroblasts expressing hTERT and SV40 early region (BJ-EHLT) and RasVal12 transformed BJ fibroblasts (BJ-Ras) were supplied by R. Weinberg (Whitehead Institute for Biomedical Research) [17, 42]. CAL33 cells were provided in December 2013 through a Material Transfer Agreement with the Oncopharmacology Laboratory, Centre Antoine Lacassagne where they had initially been isolated [43-44]. U2OS cells were a generous gift of Dr. Bluthgen (Institute of Pathology, Charité Universitätsmedizin Berlin). Cells were regularly tested for the presence of mycoplasma. A375 cells expressing
Tet repressor were transfected with pcDNA4/TO and selection of positive cells was made with $500 \mu \mathrm{g} / \mathrm{mL}$ zeocin (Invivogen). After selection, clones were isolated and tested for tetracycline inducible over-expression of the constructs. At least two independent clones were used in every experiment of this study and cells were kept in selection throughout the course of each experiment.

\section{Cellular assays}

Time course stimulation with serum was performed on G0 arrested BJ cells obtained after a 24 hours serum starvation. Cells were stimulated with $10 \%$ heat-inactivated fetal calf serum and lyzed at different time points. PD184352 (Axon Medchem) MEK inhibitor was used to inhibit ERK1/2 activity at a concentration of $5 \mu \mathrm{M}$. Clonogenic growth assays were conducted with $2.10^{3}$ cells seeded onto six well plates in DMEM supplemented with $10 \%$ serum and, when indicated, $1 \mu \mathrm{g} / \mathrm{mL}$ tetracycline for 10 days. Dishes were then stained with giemsa (Fluka). The senescence -galactosidase staining kit (Cell signaling Technology) was used according to the manufacturer's protocol to assay for senescence associated beta-galactosidase expression in cells over-expressing different variants of the TRF2 gene. The cell cycle analysis was performed by flow cytometry. Cells were rinsed in PBS, fixed in ice cold $70 \%$ ethanol and stained in a solution containing $50 \mu \mathrm{g} / \mathrm{mL}$ PI and $75 \mathrm{kU} / \mathrm{mL}$ RNAse A for 15 minutes in the dark at room temperature. Samples were analyzed on a FACS calibur (Becton-Dickinson) and cell cycle distribution and percentage of apoptotic cells were determined using WinMDI software (Scripps Research Institute).

\section{Proximity ligation assay}

Cells were, fixed with 4\% PFA, and permeabilized and blocked with $0.1 \%$ Triton X-100, 10\% BSA in PBS. Cells were then incubated with primary antibodies to TRF2 (Imgenex) and p-ERK1/2 (Sigma-Aldrich), then with the appropriate, DNA-linked secondary antibodies, analyzed with the Duolink assay according to the manufacturer's instructions. The same protocol was applied to histological tumor sections.

\section{Immunofluorescence (IF)-FISH}

IF-FISH was performed as previously described (Sfeir and De Lange, Science 2012). Briefly, cells grown at low density on glass coverslips, prefixed in PBS-1\% PFA for 2 minutes, permeabilized in PBS- $0.1 \%$ Triton X-100 for 15 minutes and then fixed in PBS-4\%PFA for 10 minutes. Cells were then saturated in PBS- $0.1 \%$ Triton X-100-3\% fat free milk for 30 minutes, incubated for $2 \mathrm{~h}$ with the 53BP1 antibody (Novus Biologicals) and washed three times in the saturation solution, followed by incubation for 1 hour with an anti-rabbit Alexa 594-conjugated IgG antibody 
(Invitrogen). Cells were then post-fixed for 10 minutes in PBS-2\%PFA, dehydrated through an ethanol series and air dried. $0,3 \mathrm{ng} / \mu \mathrm{L}$ in $70 \%$ formamide $10 \mathrm{mM}$ - Tris $\mathrm{pH} 7.2-1 \%$ blocking reagent (Roche) (wash 1 solution) FISH TelCFITC telomeric probe (PNA Bio) was hybridized at $90^{\circ} \mathrm{C}$ for 15 minutes and 2 hours at $65^{\circ} \mathrm{C}$, washed twice in wash 1 solution, washed twice in a $50 \mathrm{mM}$ Tris $\mathrm{pH} 7,2,-150 \mathrm{mM}$ $\mathrm{NaCl}-0,05 \%$ Tween 20 solution and nuclear staining was performed with with Hoechst 33342 (Invitrogen). Cells were mounted onto slides with citifluor (Citifluor Ltd.) and imaged using an LSM Exciter confocal microscope (Zeiss) with a $63 \mathrm{X}$ plan Apo oil-immersion objective. Images analyses and post-treatment was made using ImageJ software $(\mathrm{NIH})$.

\section{Immunoprecipitation}

Exponentially growing cells were lyzed with $500 \mu \mathrm{L}$ per $60 \mathrm{~mm}$ dish of TNE buffer $(50 \mathrm{mM}$ Tris-HCl pH 8, 150 mM NaCl, 1 mM EDTA, 1\% Triton X100) supplemented with phosphatase inhibitors (10 mM NaF, $2 \mu \mathrm{M} \mathrm{Na} 3 \mathrm{VO} 4$, $20 \mathrm{mM} \beta$-glycerophosphate) and a protease inhibitor cocktail (Roche Diagnostic). Immuno-precipitation assays were performed on protein $\mathrm{G}$ sepharose beads with either $3 \mu \mathrm{g}$ of the polyclonal phospho-TRF2 antibody or $2 \mu \mathrm{g}$ of a TRF2 antibody (Imgenex IMG-124A) on $200 \mu \mathrm{g}$ to $1 \mathrm{mg}$ proteins, incubated for 16 hours at $4^{\circ} \mathrm{C}$. Immunoprecipitated proteins were visualized with antiTRF2 or anti-PX[phospho]SP antibodies respectively. The anti-phosphorylated forms of TRF2 were obtained as the following: anti-phosphopeptide sera were generated by Eurogentec (Liege, Belgium) by injecting two rabbits each with the following phosphopeptide. $\mathrm{NH}_{2}-\mathrm{LPA}$ $-\left(\mathrm{PO}_{3} \mathrm{H}_{2}\right)$ - SPALKNKR-COOH coupled to KLH (the boldface underlined " $\mathrm{S}$ " represents the serine targeted by ERK1/2). Sera were affinity-purified by passing them first over an EAH-Sepharose 4B column (Amersham Biosciences, Inc.) to which the unphosphorylated peptide was coupled and the flow-through was collected. The nonretained fraction was then passed over a column to which the phosphorylated peptide was bound. Specific IgG were then eluted with $100 \mathrm{mM}$ glycine $(\mathrm{pH} 2.8)$ and neutralized in Tris $3 \mathrm{mM}$, pH 11.

\section{Tumor xenograft formation and size evaluation}

$10^{6}$ cells were injected subcutaneously into the flanks of 5-week-old nude (nu/nu) female mice of approximately 25 grams (Janvier, France). Tumor volume $\left(\mathrm{v}=\mathrm{L} \mathrm{x}^{2} \times 0.52[45]\right)$ was determined in parallel using a caliper.

\section{ACKNOWLEDGMENTS}

We thank Dr. Scott Kenneth Parks for editing assistance.

\section{CONFLICTS OF INTEREST}

The authors disclose no potential conflict of interest.

\section{GRANT SUPPORT}

This work was supported by a French National Institute for Cancer Research grant (INCa, program TELOFUN) to EG, VP, and GP, the French association for cancer research (ARC), the Fondation de France, the association Monégasque "Cordons de Vie" (www. cordonsdevie.com) and the Ligue Nationale Contre le Cancer (EG: "équipe labélisée”). This work was performed using the microscopy facility of IRCAN (PICMI).

\section{Authors' contributions}

Conception and design: Gilson, E, Renno, T and Pagès, G

Development of methodology: Picco, V, Coste, I, Giraud-Panis, MJ

Acquisition of data: Picco, V, Coste, I, GiraudPanis, MJ

Analysis and interpretation of data: Gilson, E, Renno, $\mathrm{T}$ and Pagès, $\mathrm{G}$

Writing, review, and/or revision of the manuscript:

Gilson, E, Renno, T and Pagès, G

Administrative, technical, or material support:

Gilson, E, Renno, T and Pagès, G

Study supervision: Pagès, G

\section{REFERENCES}

1. Blackburn EH, Greider CW and Szostak JW. Telomeres and telomerase: the path from maize, Tetrahymena and yeast to human cancer and aging. Nat Med. 2006; 12:1133-1138.

2. Giraud-Panis MJ, Pisano S, Benarroch-Popivker D, Pei $\mathrm{B}$, Le Du MH and Gilson E. One identity or more for telomeres? Front Oncol. 2013; 3:48.

3. de Lange T. Shelterin: the protein complex that shapes and safeguards human telomeres. Genes Dev. 2005; 19:2100-2110.

4. Poulet A, Pisano S, Faivre-Moskalenko C, Pei B, Tauran Y, Haftek-Terreau Z, Brunet F, Le Bihan YV, Ledu MH, Montel F, Hugo N, Amiard S, Argoul F, Chaboud A, Gilson E and Giraud-Panis MJ. The N-terminal domains of TRF1 and TRF2 regulate their ability to condense telomeric DNA. Nucleic Acids Res. 2012; 40:2566-2576.

5. Fouche N, Cesare AJ, Willcox S, Ozgur S, Compton SA and Griffith JD. The basic domain of TRF2 directs binding to DNA junctions irrespective of the presence of TTAGGG repeats. J Biol Chem. 2006; 281:37486-37495.

6. Kim H, Lee OH, Xin H, Chen LY, Qin J, Chae HK, Lin SY, Safari A, Liu D and Songyang Z. TRF2 functions as 
a protein hub and regulates telomere maintenance by recognizing specific peptide motifs. Nat Struct Mol Biol. 2009; 16:372-379.

7. Chen Y, Yang Y, van Overbeek M, Donigian JR, Baciu P, de Lange $\mathrm{T}$ and Lei $\mathrm{M}$. A shared docking motif in TRF1 and TRF2 used for differential recruitment of telomeric proteins. Science. 2008; 319:1092-1096.

8. Hanaoka S, Nagadoi A and Nishimura Y. Comparison between TRF2 and TRF1 of their telomeric DNA-bound structures and DNA-binding activities. Protein Sci. 2005; 14:119-130.

9. Court R, Chapman L, Fairall L and Rhodes D. How the human telomeric proteins TRF1 and TRF2 recognize telomeric DNA: a view from high-resolution crystal structures. EMBO Rep. 2005; 6:39-45.

10. Broccoli D, Smogorzewska A, Chong L and de Lange T. Human telomeres contain two distinct Myb-related proteins, TRF1 and TRF2. Nat Genet. 1997; 17:231-235.

11. Bilaud T, Brun C, Ancelin K, Koering CE, Laroche T and Gilson E. Telomeric localization of TRF2, a novel human telobox protein. Nat Genet. 1997; 17:236-239.

12. Bilaud T, Koering CE, Binet-Brasselet E, Ancelin K, Pollice A, Gasser SM and Gilson E. The telobox, a Myb-related telomeric DNA binding motif found in proteins from yeast, plants and human. Nucleic Acids Res. 1996; 24:1294-1303.

13. Okamoto K, Bartocci C, Ouzounov I, Diedrich JK, Yates JR, 3rd and Denchi EL. A two-step mechanism for TRF2mediated chromosome-end protection. Nature. 2013; 494:502-505.

14. Ye J, Lenain C, Bauwens S, Rizzo A, Saint-Leger A, Poulet A, Benarroch D, Magdinier F, Morere J, Amiard S, Verhoeyen E, Britton S, Calsou P, Salles B, Bizard A, Nadal $\mathrm{M}$, et al. TRF2 and apollo cooperate with topoisomerase 2alpha to protect human telomeres from replicative damage. Cell. 2010; 142:230-242.

15. Nijjar T, Bassett E, Garbe J, Takenaka Y, Stampfer MR, Gilley D and Yaswen P. Accumulation and altered localization of telomere-associated protein TRF2 in immortally transformed and tumor-derived human breast cells. Oncogene. 2005; 24:3369-3376.

16. Diala I, Wagner N, Magdinier F, Shkreli M, Sirakov M, Bauwens S, Schluth-Bolard C, Simonet T, Renault VM, Ye J, Djerbi A, Pineau P, Choi J, Artandi S, Dejean A, Plateroti $\mathrm{M}$, et al. Telomere protection and TRF2 expression are enhanced by the canonical Wnt signalling pathway. EMBO Rep. 2013; 14:356-363.

17. Biroccio A, Cherfils-Vicini J, Augereau A, Pinte S, Bauwens S, Ye J, Simonet T, Horard B, Jamet K, Cervera L, MendezBermudez A, Poncet D, Grataroli R, de Rodenbeeke CT, Salvati E, Rizzo A, et al. TRF2 inhibits a cell-extrinsic pathway through which natural killer cells eliminate cancer cells. Nat Cell Biol. 2013; 15:818-828.

18. Begemann S, Galimi F and Karlseder J. Moderate expression of TRF2 in the hematopoietic system increases development of large cell blastic T-cell lymphomas. Aging (Albany NY). 2009; 1:122-130. doi: 10.18632/aging. 122.

19. Cookson JC and Laughton CA. The levels of telomerebinding proteins in human tumours and therapeutic implications. Eur J Cancer. 2009; 45:536-550.

20. Nakanishi K, Kawai T, Kumaki F, Hiroi S, Mukai M, Ikeda E, Koering $\mathrm{CE}$ and Gilson E. Expression of mRNAs for telomeric repeat binding factor (TRF)-1 and TRF2 in atypical adenomatous hyperplasia and adenocarcinoma of the lung. Clin Cancer Res. 2003; 9:1105-1111.

21. Hu H, Zhang Y, Zou M, Yang $\mathrm{S}$ and Liang XQ. Expression of TRF1, TRF2, TIN2, TERT, KU70, and BRCA1 proteins is associated with telomere shortening and may contribute to multistage carcinogenesis of gastric cancer. J Cancer Res Clin Oncol. 2010; 136:1407-1414.

22. Yang D, Xiong Y, Kim H, He Q, Li Y, Chen R and Songyang Z. Human telomeric proteins occupy selective interstitial sites. Cell Res. 2011; 21:1013-1027.

23. Simonet T, Zaragosi LE, Philippe C, Lebrigand K, Schouteden C, Augereau A, Bauwens S, Ye J, Santagostino M, Giulotto E, Magdinier F, Horard B, Barbry P, Waldmann $\mathrm{R}$ and Gilson $\mathrm{E}$. The human TTAGGG repeat factors 1 and 2 bind to a subset of interstitial telomeric sequences and satellite repeats. Cell Res. 2011; 21:1028-1038.

24. Blanco R, Munoz P, Flores JM, Klatt P and Blasco MA. Telomerase abrogation dramatically accelerates TRF2induced epithelial carcinogenesis. Genes Dev. 2007; 21:206-220.

25. Biroccio A, Rizzo A, Elli R, Koering CE, Belleville A, Benassi B, Leonetti C, Stevens MF, D'Incalci M, Zupi $\mathrm{G}$ and Gilson E. TRF2 inhibition triggers apoptosis and reduces tumourigenicity of human melanoma cells. Eur J Cancer. 2006; 42:1881-1888.

26. Munoz P, Blanco R, Flores JM and Blasco MA. XPF nuclease-dependent telomere loss and increased DNA damage in mice overexpressing TRF2 result in premature aging and cancer. Nat Genet. 2005; 37:1063-1071.

27. Chi Y, Welcker M, Hizli AA, Posakony JJ, Aebersold R and Clurman BE. Identification of CDK2 substrates in human cell lysates. Genome Biol. 2008; 9:R149.

28. Holmes JK and Solomon MJ. A predictive scale for evaluating cyclin-dependent kinase substrates. A comparison of p34cdc2 and p33cdk2. J Biol Chem. 1996; 271:25240-25246.

29. Garai A, Zeke A, Gogl G, Toro I, Fordos F, Blankenburg H, Barkai T, Varga J, Alexa A, Emig D, Albrecht M and Remenyi A. Specificity of linear motifs that bind to a common mitogen-activated protein kinase docking groove. Sci Signal. 2012; 5:ra74.

30. Daub H, Olsen JV, Bairlein M, Gnad F, Oppermann FS, Korner R, Greff Z, Keri G, Stemmann O and Mann M. Kinase-selective enrichment enables quantitative phosphoproteomics of the kinome across the cell cycle. Mol Cell. 2008; 31:438-448. 
31. Coste I, Le Corf K, Kfoury A, Hmitou I, Druillennec S, Hainaut P, Eychene A, Lebecque S and Renno T. Dual function of MyD88 in RAS signaling and inflammation, leading to mouse and human cell transformation. J Clin Invest. 2010; 120:3663-3667.

32. Tanoue $\mathrm{T}$, Adachi $\mathrm{M}$, Moriguchi $\mathrm{T}$ and Nishida E. A conserved docking motif in MAP kinases common to substrates, activators and regulators. Nat Cell Biol. 2000; 2:110-116.

33. Chen LY, Zhang Y, Zhang Q, Li H, Luo Z, Fang H, Kim SH, Qin L, Yotnda P, Xu J, Tu BP, Bai Y and Songyang Z. Mitochondrial localization of telomeric protein TIN2 links telomere regulation to metabolic control. Mol Cell. 2012; 47:839-850.

34. Pagès G, Lenormand P, L'Allemain G, Chambard JC, Meloche S and Pouysségur J. Mitogen-activated protein kinases $\mathrm{p} 42^{\text {mapk }}$ and $\mathrm{p} 44^{\text {mapk }}$ are required for fibroblast proliferation. Proc Natl Acad Sci USA. 1993; 90:8319-8323.

35. Fujita K, Horikawa I, Mondal AM, Jenkins LM, Appella E, Vojtesek B, Bourdon JC, Lane DP and Harris CC. Positive feedback between p53 and TRF2 during telomere-damage signalling and cellular senescence. Nat Cell Biol. 2010; 12:1205-1212.

36. Feldser DM and Greider CW. Short telomeres limit tumor progression in vivo by inducing senescence. Cancer Cell. 2007; 11:461-469.

37. Frescas D and de Lange T. TRF2-tethered TIN2 can mediate telomere protection by TPP1/POT1. Mol Cell Biol. 2014; 34:1349-1362. doi: 10.1128/MCB.01052-13.

38. Kim SH, Beausejour C, Davalos AR, Kaminker P, Heo SJ and Campisi J. TIN2 mediates functions of TRF2 at human telomeres. J Biol Chem. 2004; 279:43799-43804.
39. Roberts EC, Shapiro PS, Nahreini TS, Pages G, Pouyssegur $\mathrm{J}$ and Ahn NG. Distinct cell cycle timing requirements for extracellular signal-regulated kinase and phosphoinositide 3-kinase signaling pathways in somatic cell mitosis. Mol Cell Biol. 2002; 22:7226-7241.

40. Mattern KA, Swiggers SJ, Nigg AL, Lowenberg B, Houtsmuller AB and Zijlmans JM. Dynamics of protein binding to telomeres in living cells: implications for telomere structure and function. Mol Cell Biol. 2004; 24:5587-5594.

41. Volmat V, Camps M, Arkinstall S, Pouyssegur J and Lenormand $\mathrm{P}$. The nucleus, a site for signal termination by sequestration and inactivation of p42/p44 MAP kinases. J Cell Sci. 2001; 114:3433-3443.

42. Hahn WC, Counter CM, Lundberg AS, Beijersbergen RL, Brooks MW and Weinberg RA. Creation of human tumour cells with defined genetic elements. Nature. 1999; 400:464-468.

43. Magne N, Fischel JL, Dubreuil A, Formento P, Marcie S, Lagrange JL and Milano G. Sequence-dependent effects of ZD1839 ('Iressa') in combination with cytotoxic treatment in human head and neck cancer. Br J Cancer. 2002; 86:819-827.

44. Magne N, Fischel JL, Dubreuil A, Formento P, Poupon MF, Laurent-Puig P and Milano G. Influence of epidermal growth factor receptor (EGFR), p53 and intrinsic MAP kinase pathway status of tumour cells on the antiproliferative effect of ZD1839 ("Iressa"). Br J Cancer. 2002; 86:1518-1523.

45. Auerbach R, Morrissey LW and Sidky YA. Regional differences in the incidence and growth of mouse tumors following intradermal or subcutaneous inoculation. Cancer Res. 1978; 38:1739-1744. 